\title{
Comparison of Volatile Compounds Produced in Model Cheese Medium Deacidified by Debaryomyces hansenii or Kluyveromyces marxianus
}

\author{
M.-N. Leclercq-Perlat, G. Corrieu, and H.-E. Spinnler \\ Unité Mixte de Recherche Génie et de Microbiologie des Procédés Alimentaires (UMR G.M.P.A.), \\ F-78 850 Thiverval-Grignon, France
}

\begin{abstract}
The aroma of a deacidified cheese medium is the result of the overall perception of a large number of molecules belonging to different classes. The volatile compound composition of (60\%) cheese medium ( $\mathrm{pH} 5.8)$ deacidified by Debaryomyces hansenii $\left(\mathrm{DCM}_{\mathrm{Dh}}\right)$ was compared with the one deacidified by Kluyveromyces marxianus $\left(\mathrm{DCM}_{\mathrm{Km}}\right)$. It was determined by dynamic headspace extraction, followed by gas chromatography separation and quantification as well as by mass spectrometry identification. Whatever the media tested, a first class of volatile compounds can be represented by the ones not produced by any of the yeasts, but some of them are affected by $K$. marxianus or by $D$. hansenii. A second class of volatile compounds can be represented by the ones produced by $K$. marxianus, which were essentially esters. Their concentrations were generally higher than their thresholds, explaining the $\mathrm{DCM}_{\mathrm{Km}}$ global fruity odor. A third class can be represented by the ones generated by $D$. hansenii, which were essentially methyl ketones with fruity, floral (rose), moldy, cheesy, or wine odor plus 2-phenylethanol with a fadedrose odor. The impact of methyl ketones on the $\mathrm{DCM}_{\mathrm{Dh}}$ global flavor was lower than the impact of 2-phenylethanol and even negligible. Therefore, the global fadedrose odor of $D$. hansenii DCM can be explained by a high concentration of 2-phenylethanol.

(Key words: deacidified cheese medium, Kluyveromyces marxianus, Debaryomyces hansenii, volatile compound composition)
\end{abstract}

Abbreviation key: DCM = deacidified cheese medium, $\mathbf{D h}=$ Debaryomyces hansenii, $\mathbf{K m}=$ Kluyveromyces marxianus, YEGC = yeast extract glucose chloramphenicol.

\section{INTRODUCTION}

In a soft cheese, the surface microflora generates flavors during the ripening (Martin et al., 1999). Yeasts

Received May 21, 2003.

Accepted September 25, 2003.

Corresponding author: M.-N. LecClercq-Perlat; e-mail: perlat@ grignon.inra.fr.
(Hanssen et al., 1984; Lee and Richard, 1984; Martin et al., 1999) play a role in the development of aroma through the production of a wide variety of volatile compounds (Molimard and Spinnler, 1996; Sable and Cottenceau, 1999; Cristiani and Monnet, 2001). The yeasts contribute to the flavor indirectly by the production of proteolytic and lipolytic enzymes and directly by the production of aroma components (Fleet, 1990; Roostita and Fleet, 1996; Jakobsen and Narvhus, 1996; Klein et al., 2002). During ripening, the roles of yeasts in the appearance and in the flavor continue in relation to the growth of the other flora (Reps, 1993).

To better understand the impact of yeasts on cheese flavor, many authors have proposed to use a cheese model medium made with curd and water. Depending on the properties of the different strains present, yeasts may have a positive (increase in $\mathrm{pH}$, etc.) or a negative (unpleasant taste, etc.) effect on ripening (Fleet, 1990; Eliskases-Lechner and Ginzinger, 1995; Tzanetakis et al., 1998; Martin et al., 1999; Petersen et al., 2002; Carreira et al., 2002). The predominant species of yeasts in the cheese rind are Kluyveromyces lactis or K. marxianus and Debaryomyces hansenii (EliskasesLechner and Ginzinger, 1995; Welthagen and Viljoen, 1999). Kluyveromyces spp. produces large amounts of alcohols, aldehydes, esters, and terpenes when cultured alone in cheese slurries (Martin et al., 2001). Ethyl acetate synthesis by $K$. fragilis is catalyzed by both an esterase (a constitutive enzyme) and alcohol-acetyl transferase (an inducible one) (Kallel-Mhiri and Miclo, 1993). Kluyveromyces lactis produced a variety of esters, ethyl acetate being the major one (Arfi et al., 2002). The production of ethyl and butyl acetates during ripening of a Camembert cheese followed the growth of this yeast (Leclercq-Perlat et al., 2003b). From a D. hansenii strain, an esterase, which was able to hydrolyze the esters, was isolated (Besancon et al., 1995). It may be a reason why this yeast cannot produce large quantities of esters. To our knowledge, the production of aroma from $D$. hansenii has not been analyzed in detail in isolation from interactions with some other cheese microorganisms. In their former study (Leclercq-Perlat et al., 2003a), the color of Brevibacterium linens biofilms was found to be dependent on the deacidification yeast 
used. It was equally observed that the odor of a deacidified cheese medium (DCM) was dependent on the yeast used. Debaryomyces hansenii spawned a typical and strong wine-faded rose odor, while $K$. marxianus generated an ethereal fruity (apple and pineapple) aroma, which was close to the one characteristic of young Camembert in the ripening chamber. For these reasons, it was decided to focus attention on the volatile compound composition of the initial slurry (reference), the $\mathrm{DCM}_{\mathrm{Dh}}$ or the $\mathrm{DCM}_{\mathrm{Km}}$.

In this study of a Munster cheese curd, the production of volatile compounds by pure cultures of 2 yeasts $(D$. hansenii and $K$. marxianus) was considered. It was measured by dynamic headspace-gas chromatographymass spectrometry analysis. This analytical approach involved extraction, separation, identification, and quantification of the extracted volatile compounds. It has been successfully applied to dairy products (Imhof and Bosset, 1991; Engels et al., 1997). However, dynamic headspace conditions differed between studies, depending on the studied food products. Consequently, those conditions, as well as a sample preparation, were first optimized to obtain good sensitivity and repeatability of quantification (Berger et al., 1999; Leclercq-Perlat et al., 2003b). Using this technique, a better understanding of the role of yeasts in aroma production on cheese slurries was possible.

\section{MATERIALS AND METHODS}

\section{Biological Material}

Debaryomyces hansenii (strain 304, LGMPA collection, Grignon, France) and K. marxianus (strain Laf5, Chr. Hansen, Arpajon, France) were used.

\section{Preparation of $K$. marxianus and $D$. hansenii Cheese Starters}

The starter of each yeast strain was prepared as described by Leclercq-Perlat et al. (2003a).

\section{Cheese Medium Preparation}

Muenster cheeses used to prepare the slurries were obtained from the industrial factory, Coopérative Agricole Laitière (BP2; 54450 Blâmont, France). Kept on the first day of cheese making, they were not salted and were not seeded with ripening flora. They were frozen at $-80^{\circ} \mathrm{C}$ to prevent enzymatic reactions and auto-oxidation and kept frozen for less than 6 mo.

After thawing, $240 \mathrm{~g}$ of cheese was ground in a mortar and transferred to a 1-L flask containing $160 \mathrm{~mL}$ of sterile water $\left(120^{\circ} \mathrm{C}, 20 \mathrm{~min}\right)$. This preparation was sterilized at $100^{\circ} \mathrm{C}$ for $10 \mathrm{~min}$ to kill the lactic bacteria.
When its temperature was close to $60^{\circ} \mathrm{C}$, it was homogenized with an Ultra-Turrax T25 grinder (Janke \& Kunkel, IKA-Labortechnik, Staufel, Germany) (1 min, $24,000 \mathrm{rpm})$. After cooling down to $30^{\circ} \mathrm{C}$, one of the yeast starters $\left(10^{6} \mathrm{cfu} / \mathrm{mL}\right)$ was inoculated. After a second homogenization (Ultra-Turrax, $40 \mathrm{~s}, 13,500 \mathrm{rpm}$ ), 300 $\mathrm{mL}$ of this medium was transferred to a $1-\mathrm{L}$ conical flask corked with a cellulose cork that was previously sterilized $\left(120^{\circ} \mathrm{C}, 20 \mathrm{~min}\right)$. Then, this medium (initial $\mathrm{pH}$ close to 4.8) was incubated in darkness at $25^{\circ} \mathrm{C}$ while being shaken (150 rpm) until reaching $\mathrm{pH} 5.8$. Five independent trials were carried out to test the repeatability of this preparation.

\section{Analysis of Volatile Compounds Present in Cheese Suspensions (Reference and DCM)}

Gas chromatography and mass spectrometry measurements. The analysis of volatile compound composition was performed as described by LeclercqPerlat et al. (2003b). The volatile compounds were extracted with a dynamic headspace analyzer (purge and trap concentrator, model 7695A, Hewlett-Packard, Avondale, PA). Each sample tube was connected to the apparatus and heated at $60^{\circ} \mathrm{C}$ for $10 \mathrm{~min}$. Then it was purged with helium (99\% of purity) at a flow rate of $30 \mathrm{~mL} / \mathrm{min}$ for $15 \mathrm{~min}$. The volatile compounds were extracted by adsorption onto a porous-polymer-adsorbent Tenax trap column (Teckmar Inc., Cincinnati, $\mathrm{OH}$ ) at room temperature, which was then heated to $225^{\circ} \mathrm{C}$ for $2 \mathrm{~min}$ to desorb them. The compounds eluted were directly transferred at $150^{\circ} \mathrm{C}$ to the head of a capillary column where they were cryofocused at $-150^{\circ} \mathrm{C}$. Water was removed by condensation with the in-line system MCS (Hewlett-Packard) between the Tenax trap and the cryofocusing system.

The condensed compounds were separated by GC (model 6890, Hewlett-Packard) by heating the interface to $180^{\circ} \mathrm{C}$ for $1 \mathrm{~min}$. They were automatically injected (splitless) into a nonpolar capillary column (HP-5MS; $30 \mathrm{~m} \times 0.25 \mathrm{~mm}$ and film thickness $0.25 \mu \mathrm{m}$ ) at a helium flow rate of $1.6 \mathrm{~mL} / \mathrm{min}$. The oven temperature was kept at $4^{\circ} \mathrm{C}$ for $8 \mathrm{~min}$. Then, temperature increases were programmed, from 5 to $50^{\circ} \mathrm{C}$ at $3^{\circ} \mathrm{C} / \mathrm{min}$, from 50 to $100^{\circ} \mathrm{C}$ at $5^{\circ} \mathrm{C} / \mathrm{min}$, and to the final temperature of $150^{\circ} \mathrm{C}$ at $10^{\circ} \mathrm{C} / \mathrm{min}$. The oven stayed at this temperature for $5 \mathrm{~min}$. The GC column was connected directly to a mass selective detector (HP6890/5972). The specifications of the method used were summarized by Berger et al. (1999). The electron impact energy was set at 70 $\mathrm{eV}$, and data were collected in the range of 29 to 300 atomic mass units at a scan rate of $1.68 \mathrm{scans} / \mathrm{s}$.

Before analysis, each cheese medium sample was diluted to $1 / 100$ with $\left(4^{\circ} \mathrm{C}\right)$ cold Milli-Q water (Millipore 
system) and its $\mathrm{pH}$ after dilution was $5.80 \pm 0.05$. Prior to headspace analysis, this procedure maintained the same conditions of volatile suspension for all the samples (Mariaca and Bosset, 1997).

This analysis was carried out on 3 independent cultureS of the same type. Each culture was analyzed in triplicate by GC/MS. The mean of the abundances obtained from each of the 3 cultures was called "mean abundance."

Selection and quantification of some volatile compounds produced during deacidification. The volatiles produced in the cheese samples were identified by GC comparison with the one of the pure compounds (retention time and mass spectra). The concentrations of 12 compounds reflected on the main flavor pathways were determined using a calibration curve made with the pure compounds. These compounds were purchased from Aldrich (Sigma-Aldrich chemistry SARL, Saint Quentin Fallavier, France) except isoamyl acetate and ethyl acetate from Fischer Scientific (Elancourt, France) and ethyl acetate from VWR (Fontenay sous Bois, France), all with the highest purity available. Known amounts of these compounds were added to a reference cheese medium at various concentrations $(0$, $0.25,0.50,0.75,1.0,2.0$, and $5.0 \mu \mathrm{L} / \mathrm{L})$. For each of these concentrations, triplicate samples of reference cheese medium were prepared and submitted to headspace analysis 3 times. The determination of calibration curves was carried out as described by Leclercq-Perlat et al. (2003b).

This analysis was carried out on 5 reference as well as $5 \mathrm{DCM}_{\mathrm{Km}}$ and $5 \mathrm{DCM}_{\mathrm{Dh}}$ independent suspensions. Each sample was analyzed in triplicate by GC/MS to determine the culture concentration. The mean concentration was the arithmetic average of 5 measurements (one per culture).

\section{RESULTS}

The ratio of abundance observed in $\mathrm{DCM}_{\mathrm{Dh}}$ to abundance observed in $\mathrm{DCM}_{\mathrm{Km}}$ (noted $\frac{A_{D H}}{A_{K M}}$ ) was used to estimate the influence of volatile compound production by the yeast.

Volatile compounds isolated in cheese slurries may be ranked into 3 classes: 1 ) the ones that appeared in all tested media, 2) the ones produced by $K$. marxianus, and 3 ) the ones generated by $D$. hansenii.

\section{Volatile Compound Changes in DCM}

Volatile compounds present whatever the media tested. Table 1 shows the main volatile compounds, the flavor description from bibliography (Sable and
Cottenceau, 1999; Cristiani and Monnet, 2001), the average abundance (A) and the associated variation coefficient for each yeast as well as the ratio $\frac{A_{D H}}{A_{K M}}$ and the yeast involved in its production. The main volatile compounds isolated from DCM may be classified into 2 subclasses:

Subclass 1: These compounds were not produced by any of the yeasts (ratio $\mathrm{A}_{\mathrm{DH}} / \mathrm{A}_{\mathrm{KM}}$ close to 1 ). Their abundance in DCM did not appear different from the reference cheese medium. These volatile compounds were propanal, heptanal, 3-methyl-1-butanal, octanal, dimethyldisulphide, or ethyl hexanoate.

Subclass 2: These components were found in the reference cheese medium but levels were much lower than in DCM (results not shown). Their abundance was dependent on the yeast used. Among the components whose abundance changed the most, some (acetaldehyde, butanol, hexanal, nonanal, or decanal) were essentially produced by $K$. marxianus (ratio $\mathrm{A}_{\mathrm{DH}} / \mathrm{A}_{\mathrm{KM}}$ significantly lower than 1 ) and some (isobutyraldehyde, benzaldehyde, 2-methyl-1-butanal, 2methyl-1-propanol, 2-methyl-1-butanol and 2-undecanone) were essentially generated by $D$. hansenii (ratio $\mathrm{A}_{\mathrm{DH}} / \mathrm{A}_{\mathrm{KM}}$ significantly higher than 1 ).

Volatile compounds in relation to the deacidification yeast used. The quantity of the other components appeared negligible in the reference cheese medium. In the case of DCM, the other components were either apparent or negligible according to the yeast used. For the yeast involved in their production, Table 2 shows the volatile compounds, whose quantity changed considerably during deacidification, as well as their flavor description from bibliography (Sable and Cottenceau, 1999; Cristiani and Monnet, 2001), their mean abundance, the calculated variation coefficient, and their threshold. If a volatile component solution to perform the quantification was easily found, the concentration present in the medium was quantified and its value is also shown in table 2 .

The volatile compounds may be ranked as following:

The ones produced by $K$. marxianus were essentially esters with fruity odor (pineapple or banana). Except for ethyl butanoate and butyl acetate, the ester concentrations were higher than their thresholds. This fact explained that the global odor of this DCM was ester-like and fruity. One compound (ethyl acetate) was produced in large amounts.

The ones generated by $D$. hansenii were essentially methylketones with fruity, floral (rose), moldy, cheesy, or wine odors plus 2-phenylethanol with rose and wine odors. The methylketone concentrations were much lower than their thresholds. Therefore, their impact on the global flavor of the DCM was low 
Table 1. Changes in the main volatile compounds observed, the flavor note, the mean abundance (A) and the associated variation coefficient (CV \%), the ratio $A_{D H} / A_{K M}$ as well as the main yeast involved in their production, whatever the deacidified media tested. "Mean abundance" was the arithmetic average of three measurements (one per culture). For each compound, abundance was obtained by integrating the T.I.C. peaks. R, reference medium; DH, D. hansenii and KM, K. marxianus. NR, not reported.

\begin{tabular}{|c|c|c|c|c|c|c|c|}
\hline \multirow[b]{2}{*}{$\begin{array}{l}\text { Volatile } \\
\text { Compounds }\end{array}$} & \multirow[b]{2}{*}{ Flavor $^{1,2}$} & \multicolumn{2}{|c|}{ D. hansenii } & \multicolumn{2}{|c|}{ K. marxianus } & \multirow{2}{*}{$\frac{A_{D h}}{A_{K m}}$} & \multirow[b]{2}{*}{$\begin{array}{l}\text { Yeast } \\
\text { involved }\end{array}$} \\
\hline & & $\begin{array}{l}\text { Mean } \\
\text { Abundance }\end{array}$ & $\begin{array}{l}\mathrm{CV} \\
(\%)\end{array}$ & $\begin{array}{l}\text { Mean } \\
\text { Abundance }\end{array}$ & $\begin{array}{l}\mathrm{CV} \\
(\%)\end{array}$ & & \\
\hline Propanal & Pungent odor & $2.64 \times 10^{5}$ & 16 & $2.71 \times 10^{5}$ & 17 & 0.976 & $\mathrm{R}^{3}$ \\
\hline 3-methyl-1-Butanal & Malty, Sweet & $2.51 \times 10^{6}$ & 17 & $2.56 \times 10^{6}$ & 16 & 0.988 & $\mathrm{R}$ \\
\hline DMDS & Cabbage & $3.52 \times 10^{5}$ & 21 & $3.52 \times 10^{5}$ & 18 & 0.999 & $\mathrm{R}$ \\
\hline Heptanal & Oily, woody & $3.62 \times 10^{5}$ & 21 & $4.14 \times 10^{5}$ & 20 & 0.874 & $\mathrm{R}$ \\
\hline Ethyl Hexanoate & Pineapple, apple & $2.16 \times 10^{5}$ & 20 & $2.54 \times 10^{5}$ & 16 & 0.890 & $\mathrm{R}$ \\
\hline Octanal & Fruity & $5.44 \times 10^{5}$ & 18 & $6.05 \times 10^{5}$ & 22 & 0.899 & $\mathrm{R}$ \\
\hline Acetaldehyde & Ethereal, pungent, green & $1.82 \times 10^{6}$ & 16 & $3.86 \times 10^{6}$ & 12 & 0.472 & $\mathrm{KM}^{4}$ \\
\hline 1-Butanol & Sweet, fruity & $3.08 \times 10^{5}$ & 22 & $1.81 \times 10^{6}$ & 16 & 0.170 & KM \\
\hline Hexanal & Green, grassy & $3.11 \times 10^{5}$ & 21 & $5.09 \times 10^{5}$ & 21 & 0.611 & $\mathrm{KM}$ \\
\hline Nonanal & Fatty & $6.92 \times 10^{5}$ & 19 & $1.84 \times 10^{6}$ & 21 & 0.377 & $\mathrm{KM}$ \\
\hline Decanal & Fruity & $3.35 \times 10^{5}$ & 18 & $1.66 \times 10^{6}$ & 23 & 0.202 & $\mathrm{KM}$ \\
\hline Methylpropanal & NR & $3.19 \times 10^{6}$ & 9 & $1.06 \times 10^{6}$ & 19 & 3.017 & $\mathrm{DH}^{5}$ \\
\hline 2-Methyl-1-butanal & Green, malty & $1.60 \times 10^{6}$ & 18 & $6.23 \times 10^{5}$ & 29 & 2.568 & DH \\
\hline 2-Methyl-1-propanol & Alcoholic & $1.16 \times 10^{8}$ & 14 & $5.89 \times 10^{7}$ & 9 & 1.970 & $\mathrm{DH}$ \\
\hline 3-Methyl-1-butanol & Fruity, Alcohol & $2.32 \times 10^{8}$ & 8 & $1.56 \times 10^{8}$ & 11 & 1.488 & DH \\
\hline Benzaldehyde & Bitter almond & $7.97 \times 10^{5}$ & 14 & $5.29 \times 10^{5}$ & 17 & 1.508 & $\mathrm{DH}$ \\
\hline 2-Undecanone & Floral, rose & $1.23 \times 10^{6}$ & 19 & $1.68 \times 10^{5}$ & 24 & 7.349 & DH \\
\hline
\end{tabular}

${ }^{1}$ Sable and Cottenceau, 1999.

${ }^{2}$ Cristiani and Monnet, 2001.

${ }^{3} \mathrm{R}=$ Reference medium.

${ }^{4} \mathrm{KM}=K$. marxianus.

${ }^{5} \mathrm{DH}=D$. hansenii.

${ }^{6} \mathrm{NR}=$ Not reported.

and even negligible. The concentration of 2-phenylethanol was the highest. It explains the global odor of faded roses.

\section{DISCUSSION}

The main volatile compounds isolated from DCM may be ranked into 2 classes: the ones essentially esters with a fruity odor, generated by $K$. marxianus and the ones, essentially methylketones and 2-phenylethanol, with rose and wine flavor, produced by $D$. hansenii.

In $\mathrm{DCM}_{\mathrm{Km}}$, the main volatile component was ethyl acetate, which resulted from ethanol and lactose metabolisms. The ethanol was very abundant in the medium after deacidification whatever the yeast used (results not shown). The results were in accordance with those of Arfi et al. (2002) and Kallel-Mhiri et al. (1993). Indeed, in a synthetic medium, Kluyveromyces strains produce a variety of esters, with ethyl acetate being the major one. It was been shown that ethanol, lactose, and $\mathrm{O}_{2}$ were the direct precursors for the ethyl acetate synthesis that was affected by the carbon / nitrogen ratio and iron when $K$. fragilis was used (Kallel-Mhiri and Miclo, 1993). The ethanol and oxygen concentrations were not limited during $K$. marxianus growth but the lactose one strongly decreased. A peak of ethyl ace- tate was produced during the growth of $K$. lactis. It has been observed in a synthetic medium incubated at $25^{\circ} \mathrm{C}$ (Arfi et al., 2002) or in a model cheese ripened in industrial conditions (Leclercq-Perlat et al., 2003b). The isoamyl acetate also seemed to be important. It is admitted that this ester is issued from degradation of lactose (formation of Acetyl-coA) and of Leucine through the formation of isoamyl alcohol (Erhlich pathway). Kluyveromyces lactis was more efficient in releasing amino acids but its efficiency varied depending on the strains tested (Klein et al., 2002).

In $\mathrm{DCM}_{\mathrm{Dh}}$, the main volatile components were methylketones and 2-phenylethanol. The methylketones were issued from $\beta$-oxidation metabolisms of FFA (Molimard and Spinnler, 1996). Their concentrations were very low. The 2 main factors involved in this production may be: 1) the presence of lactose and lactate as easy assimilation sources of nutriments and 2) the FFA concentration. Lactose and lactate were favorable to the growth of $D$. hansenii and its growth was exponential (Leclercq-Perlat et al., 2003a). They were the source of lipid catabolism repression. The low concentration of FFA (results not shown) may result from this repression, and it appeared as a decisive factor for the low production of methylketones. The concentration of esters in this DCM was negligible. This result was in 
Table 2. Changes in the main volatile compounds whose abundance changed during deacidification, the odor, the mean abundance and the associated variation coefficient (CV\%), the odor threshold as well as the concentration in the cheese medium, for the yeast involved in their production. The mean concentration was the arithmetic average of 5 measurements (1/culture).

\begin{tabular}{|c|c|c|c|c|c|}
\hline $\begin{array}{l}\text { Volatile } \\
\text { compound }\end{array}$ & Flavor $^{1}$ & $\begin{array}{l}\text { Mean } \\
\text { abundance }\end{array}$ & $\mathrm{CV}(\%)$ & $\begin{array}{l}\text { Threshold } \\
(\mu \mathrm{L} / \mathrm{L})\end{array}$ & $\begin{array}{l}\text { Mean concentration } \\
(\mu \mathrm{L} / \mathrm{L})\end{array}$ \\
\hline \multicolumn{6}{|c|}{ Subclass 1: Compounds produced by $K$. marxianus } \\
\hline Ethyl acetate & Solvent, pungent & $5.22 \times 10^{8}$ & 17 & $22^{2,3}$ & $120.6 \pm 0.5$ \\
\hline Isoamyl acetate & Pear, banana & $4.17 \times 10^{7}$ & 19 & $0.002^{4,5}$ & $6.8 \pm 0.3$ \\
\hline Propyl acetate & Pineapple, banana & $1.64 \times 10^{7}$ & 20 & $0.0026^{6,7}$ & $0.196 \pm 0.013$ \\
\hline Ethyl butanoate & Pineapple & $6.88 \times 10^{5}$ & 22 & $0.6^{2,3}$ & $0.050 \pm 0.011$ \\
\hline Butyl acetate & Pineapple & $6.54 \times 10^{6}$ & 21 & $0.066^{6,8}$ & $0.731 \pm 0.036$ \\
\hline Ethyl octanoate & Pineapple & $1.84 \times 10^{6}$ & 20 & $0.00004^{6,9}$ & $0.387 \pm 0.008$ \\
\hline \multicolumn{6}{|c|}{ Subclass 2: Compounds produced by $D$. hansenii } \\
\hline 2-Butanone & Acetone & $1.90 \times 10^{6}$ & 23 & $30^{2,3}$ & $0.0452 \pm 0.0002$ \\
\hline 2-Pentanone & Acetone & $1.96 \times 10^{6}$ & 12 & $61^{2,3}$ & $0.0351 \pm 0.0005$ \\
\hline 2-Heptanone & Blue cheese, musty & $4.61 \times 10^{6}$ & 19 & $15^{2,3}$ & $0.277 \pm 0.010$ \\
\hline 2-Octanone & Fruity, moldy, green & $1.64 \times 10^{5}$ & 15 & $0.15-3.4^{2,3}$ & $0.0023 \pm 0.0002$ \\
\hline 2-Nonanone & Fruity, moldy, floral & $3.04 \times 10^{6}$ & 19 & $7.7^{10,2}$ & $0.262 \pm 0.007$ \\
\hline 2-phenylethanol & Rose, wine & $4.88 \times 10^{6}$ & 19 & $9.1^{10,11}$ & $188 \pm 1$ \\
\hline
\end{tabular}

${ }^{1}$ Sable and Cottenceau, 1999 and Cristiani and Monnet, 2001.

${ }^{2}$ Siek et al., 1969.

${ }^{3}$ Threshold in butter or oil.

${ }^{4}$ Piendl and Geiger, 1980.

${ }^{5}$ Threshold in water.

${ }^{6}$ Takeola et al., 1989.

${ }^{7}$ Threshold in air.

${ }^{8}$ Shimoda et al., 1996.

${ }^{9}$ Threshold in ripened cheese.

${ }^{10}$ Dumont et al., 1974.

${ }^{11}$ Roger et al., 1988.

accordance with those of Arfi et al. (2002). Ethyl acetate or other ester productions were not detected in synthetic medium cultures of $D$. hansenii. The main volatile component was 2-phenylethanol, its measured concentration being close to $188 \mu \mathrm{L} / \mathrm{L}$ at $62 \pm 4 \mathrm{~h}$. It came from the degradation of phenylalanine through the Erhlich pathway (Lee and Richard, 1984). The phenylalanine could be produced by: 1) lactic acid bacteria and/ or 2) the yeast. In fact, the nonproteic nitrogen was not negligible (close to $3.5 \%$ TN) (Leclercq-Perlat et al., 2003a). Debaryomyces hansenii was less efficient in releasing amino acids than Kluyveromyces strains (Klein et al., 2002). This could explain that the ester production efficiency observed in $\mathrm{DCM}_{\mathrm{Km}}$ was higher than the one obtained in $\mathrm{DCM}_{\mathrm{Dh}}$. This is coincident with the fact that cheese medium deacidified by $D$. hansenii showed the lowest ester concentrations, suggesting lesser release of peptidases into the cheese mass. According to Klein et al. (2002), peptidase release was related to cell lysis. Nevertheless, we did not investigate yeast peptidase release and cell yeast lysis, so further research on these subjects may be needed.

In conclusion, depending on the yeast cultivated, 2 classes of volatile compounds were found in DCM. Esters were essentially produced by $K$. marxianus and developed fruity odors. Their concentrations were generally higher than their thresholds, explaining the $\mathrm{DCM}_{\mathrm{Km}}$ global fruity odor. Methylketones were essentially generated by $D$. hansenii with a lower impact on the global odor. 2-Phenylethanol also produced by $D$. hansenii had a higher impact on global odor of this medium, which remained faded roses. In fact, the carbon and nitrogen substrates (Leclercq-Perlat et al., 2003a) and volatile compound analyses permitted the demonstration that DCM properties were dependent on the yeast used. Its aroma compositions were directly related to the deacidification yeast as well.

Although the Muenster curd used was the same, whatever the yeast tested, the deacidification medium was completely different. The influence of the deacidification yeast used on the $B$. linens biofilm color observed previously (Leclercq-Perlat et al., 2003a) was probably due to the differences of cheese composition observed after deacidification.

\section{ACKNOWLEDGMENTS}

This work was supported in part by the French Research Ministry by ACTIA contract no. 99.14. We are grateful to Tanis-Plant for her editorial advice. 


\section{REFERENCES}

Arfi, K., H. E. Spinnler, R. Tache, and P. Bonnarme. 2002. Production of volatile compounds by cheese-ripening yeasts: Requirement for a methanethiol donor for S-methyl thioacetate synthesis by Kluyveromyces lactis. Appl. Microbiol. Biotechnol. 58:503-510.

Berger, C., J. A. Khan, P. Molimard, N. Martin, and H. E. Spinnler. 1999. Production of sulfur flavors by ten strains of Geotrichum candidum. Appl. Environ. Microbiol. 65:5510-5514.

Besancon, X., R. Ratomahenina, and P. Galzy. 1995. Isolation and partial characterization of an esterase (EC 3.1.1.1) from a Debaryomyces hansenii strain. Netherlands Milk Dairy J. 49:97-110.

Carreira, A., K. Dillinger, F. Eliskases-Lechner, V. Loureiro, W. Ginzinger, and H. Rohm. 2002. Influence of selected factors on browning of Camembert cheese. J. Dairy Res. 69:281-292.

Cristiani, G., and V. Monnet. 2001. Food microorganisms and aromatic ester synthesis. Sci. Aliments 21:211-230.

Dumont, J. P., S. Roger, P. Cerf, and J. Adda. 1974. Une étude des composés volatiles neutres présent dans le fromage de Camembert. Lait 54:501-516.

Eliskases-Lechner, F., and W. Ginzinger. 1995. The yeast flora of surface-ripened cheeses. Milchwissenschaft 50:458-462.

Engels, W. J. M., R. Dekker, C. d. Jong, R. Neeter, and S. Visser. 1997. A comparative study of volatile compounds in the watersoluble fraction of various types of ripened cheese. Int. Dairy J. 7:255-263.

Fleet, G. H. 1990. Yeasts in dairy products. J. Appl. Bacteriol. 68:199-211.

Hanssen, H. P., E. Sprecher, and A. Klingenberg. 1984. Accumulation of volatile flavour compounds in liquid cultures of Kluyveromyces lactis strains. Z. Naturforsch. Sect. C, J. Biosci. 39:1030-1033.

Imhof, R., and J. O. Bosset. 1991. Comparison of two systems for sample preparation and injection by dynamic headspace GC analysis. HRC-J. High Res. Chromatogr. 14:621-625.

Jakobsen, M., and J. Narvhus. 1996. Yeasts and their possible beneficial and negative effects on the quality of dairy products. Int. Dairy J. 6:755-768.

Kallel-Mhiri, H., J. M. Engasser, and A. Miclo. 1993. Continuous ethyl acetate production by Kluyveromyces fragilis on whey permeate. Appl. Microbiol. Biotechnol. 40:201-205.

Kallel-Mhiri, H., and A. Miclo. 1993. Mechanism of ethyl acetate synthesis by Kluyveromyces fragilis. FEMS Microbiol. Lett. 111:201-205.

Klein, N., A. Zourani, and S. Lortal. 2002. Peptidase activity of four yeast species frequently encountered in dairy products-comparison with several dairy bacteria. Int. Dairy J. 12:853-861.

Leclercq-Perlat, M. N., G. Corrieu, and H. E. Spinnler. 2003a. The color of Brevibacterium linens depends on the yeast used for cheese deacidification. J. Dairy Sci. (accepted).

Leclercq-Perlat, M. N., E. Latrille, G. Corrieu, and H. E. Spinnler, 2003b. Controlled production of Camembert-type cheeses: Part II. Aroma component evolutions. J. Dairy Res. (accepted).

Leclercq-Perlat, M. N., A. Oumer, J. L. Bergere, H. E. Spinnler, and G. Corrieu. 2000. Behavior of Brevibacterium linens and Debaryo- myces hansenii as ripening flora in controlled production of smear soft cheese from reconstituted milk: growth and substrate consumption. J. Dairy Sci. 83:1665-1673.

Lee, C. W., and J. Richard. 1984. Catabolism of L-phenylalanine by some microorganisms of cheese origin. J. Dairy Res. 51:461-469.

Mariaca, R., and J. O. Bosset. 1997. Instrumental analysis of volatile (flavor) compounds in milk and dairy products. Lait 77:1, 13-40.

Martin, N., C. Berger, C. le Du, and H. E. Spinnler. 2001. Aroma compound production in cheese curd by coculturing with selected yeast and bacteria. J. Dairy Sci. 84:2125-2135.

Martin, N., S. Savonitto, P. Molimard, C. Berger, M. Brousse, and H. E. Spinnler. 1999. Flavor generation in cheese curd by coculturing with selected yeast, mold, and bacteria. J. Dairy Sci. 82:10721080 .

Molimard, P., and H. E. Spinnler. 1996. Review: Compounds involved in the flavor of surface mold-ripened cheeses: Origins and properties. J. Dairy Sci. 79:169-184.

Petersen, K. M., S. Westall, and L. Jespersen. 2002. Microbial succession of Debaryomyces hansenii strains during the production of Danish surface-ripened cheeses. J. Dairy Sci. 85:478-486.

Piendl, A., and E. Geiger. 1980. Technological Factors in the Formation of Esters during Fermentation. Brewers Digest 26-38.

Reps, A. 1993. Bacterial Surface-Ripened Cheeses. Pages 137-172 in Cheese: Chemistry, Physics and Microbiology. Vol. 2: Major Cheese Groups. P. F. Fox, ed. Chapman \& Hall, London, UK.

Roger, S., C. Degas, and J. C. Gripon. 1988. Production of phenyl ethyl alcohol and its esters during ripening of traditional Camembert. Food Chem. 28:129-140.

Roostita, R., and G. H. Fleet. 1996. The occurrence and growth of yeasts in Camembert and blue-veined cheeses. Int. J. Food Microbiol. 28:393-404.

Sable, S., and G. Cottenceau. 1999. Current knowledge of soft cheeses flavor and related compounds. J. Agric. Food Chem. 47:48254836.

Shimoda, M., Y. Wu, and Y. Osajima. 1996. Aroma compounds from aqueous solution of Haze (Rhus succedanea) honey determined by adsorptive column chromatography. J. Agric. Food Chem. 44:3913-3918.

Siek, T. J., I. A. Albin, E. Sath, and R. C. Lindsay. 1969. Taste thresholds of butter volatiles in deodorized butteroil medium. J. Food Sci. 34:265-267.

Takeola, G., R. G. Buttery, R. A. Flath, R. Teranishi, E. L. Wheeler, R. L. Wieczorek, and M. Guentert. 1989. Volatile constituents of pineapple. Flavor Chemistry: Trends and Developments. A.C.S. Symposium Series 388. R. Teranishi, R. G. Buttery, and S. F. Shadini, eds. Am. Chem. Soc., Washington, DC.

Tzanetakis, N., M. Hatzikamari, and E. Litopoulou-Tzanetaki. 1998. Yeasts of the surface microflora of Feta cheese. Yeasts in the dairy industry: positive and negative aspects. Pages 34-43 in Proc. Int. Dairy Fed. "Yeasts in the Dairy Industry: Positive and Negative Aspects", Copenhagen, Denmark.

Welthagen, J. J., and B. C. Viljoen. 1999. The isolation and identification of yeasts obtained during the manufacture and ripening of Cheddar cheese. Food Microbiol. 16:63-73. 